\title{
Use of Non-Partitioned Ventilator Tubing Results in Dead-Space Ventilation Hypercarbia
}

\author{
Bassem O Asaad MD, Mohammad Helwani MD, David M Wheeler RRT-NPS, \\ and Michael S O'Connor DO MPH
}

\begin{abstract}
We present a case of severe postoperative hypercarbia in a patient with severe COPD. Hypercarbia and respiratory acidosis continued to increase despite maximal ventilation, bronchodilator therapy, sedation, and paralysis. Mistaken use of non-partitioned ventilator circuit was the cause of the hypercarbia. The ventilator's self-test function failed to detect the error. We changed to a partitioned-lumen circuit, with much less ventilation dead space, and the hypercarbia resolved immediately. Key words: partitioned-lumen ventilator tubing; dead space; $\mathrm{P}_{\mathrm{aCO}}$; hypercarbia; COPD. [Respir Care 2011;56(5):698-701. (C) 2011 Daedalus Enterprises]
\end{abstract}

\section{Introduction}

Hypercarbia results from inadequate ventilation. Typically, hypercarbia arises when the physiologic dead space and metabolic demand cannot be met by the existing alveolar ventilation. $\mathrm{CO}_{2}$ production increases in hypercatabolic states such as malignant hyperthermia and thyrotoxicosis. ${ }^{1,2}$ Pathological conditions have a minimal effect on anatomical dead space, whereas physiological dead space is primarily influenced by changes in alveolar dead space. ${ }^{3}$ It is important, and can be crucial, to minimize the apparatus dead space of the ventilator circuit. Anesthesia-machine ventilators have a soda lime canister to absorb $\mathrm{CO}_{2}$, but intensive-care ventilators lack this feature, so capnography can be an important component of intensive-care monitoring. We report a case in which capnography would have allowed earlier identification of the cause of severe hypercarbia and avoided unnecessary diagnostic procedures and costs.

\section{Case Report}

A 76-year-old, 108-kg man with a history of severe COPD, responsive to bronchodilators, underwent (under

\footnotetext{
Bassem O Asaad MD is affiliated with the Department of Anesthesiology, Stony Brook University, Stony Brook, New York. Mohammad Helwani MD is affiliated with the Department of Anesthesiology, Saint Louis Veterans Affairs Medical Center, Saint Louis, Missouri. David M Wheeler RRT-NPS is affiliated with the Cardiothoracic Intensive Care Unit, The Cleveland Clinic Foundation, Cleveland, Ohio. Michael S
}

general anesthesia) urgent cystoscopy and urinary bladder clot evacuation for substantial hematuria. At the end of the 2-hour procedure, he met our extubation criteria and was extubated in the operating room, then transferred to the post-anesthesia care unit on supplemental oxygen, at $4 \mathrm{~L} /$ min via nasal cannula. Minutes after arrival in the postanesthesia care unit, he started to become hypoxic, tachypneic, and somnolent. Conservative treatment, including jaw thrust, insertion of a nasal airway, and changing the nasal cannula to a non-rebreather mask, failed to achieve any benefit. We also tried bronchodilator therapy as a last resort despite the fact that his preoperative pulmonary function test found no response to bronchodilators. Bag-valvemask ventilation gave temporary improvement.

Taking into consideration his severe COPD and the deterioration of his condition, we decided to re-intubate and mechanically ventilate him to decrease ventilation dead space and work of breathing. No hypnotics or muscle relaxant were used, as he was unconscious and rapidly deteriorating at that point. Correct endotracheal tube position was confirmed via capnography and auscultation. The ven-

O'Connor DO MPH is affiliated with the Department of Cardiothoracic Anesthesiology, The Cleveland Clinic Foundation, Cleveland, Ohio.

The authors have disclosed no conflicts of interest.

Correspondence: Mohammad Helwani MD, Department of Anesthesiology, Saint Louis Veterans Affairs Medical Center, 915 North Grand Street, Louis MO 63106. E-mail: helwanim@gmail.com.

DOI: $10.4187 /$ respcare. 01017 


\section{Non-Partitional Ventilator Tubing Results in Dead-Space Ventilation Hypercarbia}

Table 1. Ventilator Settings and Consequent Arterial Blood Gas Values*

\begin{tabular}{|c|c|c|c|c|c|c|c|c|c|c|}
\hline $\begin{array}{l}\text { Setting } \\
\text { Number }\end{array}$ & Ventilation Mode & $\begin{array}{l}\text { Tidal Volume } \\
\qquad(\mathrm{mL})\end{array}$ & $\begin{array}{l}\text { Respiratory Rate } \\
\text { (breaths/min) }\end{array}$ & PEEP & $\mathrm{F}_{\mathrm{IO}_{2}}$ & $\begin{array}{l}\text { Flow } \\
(\mathrm{L} / \mathrm{min})\end{array}$ & $\mathrm{pH}$ & $\begin{array}{c}\mathrm{P}_{\mathrm{aCO}_{2}} \\
(\mathrm{~mm} \mathrm{Hg})\end{array}$ & $\begin{array}{c}\mathrm{P}_{\mathrm{aO}_{2}} \\
(\mathrm{~mm} \mathrm{Hg})\end{array}$ & $\mathrm{HCO}_{3}$ \\
\hline 1 & Volume controlled-SIMV & 700 & 12 & 5 & 0.6 & 70 & 7.11 & 101 & 186 & 32 \\
\hline 2 & Volume controlled-SIMV & 800 & 16 & 5 & 0.6 & 70 & 7.01 & 127 & 111 & 31 \\
\hline 3 & Volume controlled-assist control & 800 & 24 & 5 & 0.6 & 80 & 7.07 & 112 & 128 & 32 \\
\hline 4 & $\begin{array}{l}\text { Volume controlled-assist control, } \\
\text { paralyzed }\end{array}$ & 900 & 30 & 5 & 0.6 & 90 & 7.05 & 120 & 131 & 32 \\
\hline 5 & Manual ventilation & & 16 & & 1.0 & & 7.35 & 46 & 285 & 25 \\
\hline
\end{tabular}

* The ventilation-setting changes were 15-20 min apart.

SIMV $=$ synchronized intermittent mechanical ventilation

tilator (840, Puritan Bennett, Pleasanton, California) was initially set to synchronized intermittent mandatory ventilation (Table 1, setting 1). There was reasonable chest movement with the mechanical ventilation. Within minutes of initiating mechanical ventilation he became increasingly somnolent, with tachycardia and hypertension. Arterial blood gas (ABG) analysis revealed severe acute respiratory acidosis (Table 1 , setting 1 ). We increased the minute ventilation $\left(\dot{\mathrm{V}}_{\mathrm{E}}\right)$ (Table 1 , setting 2$)$, but the hypercarbia persisted. He had mild expiratory rhonchi, but the chest radiograph showed no pertinent findings. We administered aerosolized albuterol, changed the ventilation mode to assist control, and increased the respiratory rate to 24 breaths/min (Table 1 , setting 3), but he continued to deteriorate. Analysis of the ventilator graphics indicated that he was synchronous with the ventilator and that there was no dynamic hyperinflation or intrinsic PEEP. He continued to trigger mechanical breaths beyond the set rate of 24 breaths/min.

We then administered additional aerosolized albuterol, sedation (propofol infusion), and a paralytic (a bolus of rocuronium), then increased both tidal volume and respiratory rate (Table 1 , setting 4 ) to manage the severe respiratory acidemia. We kept plateau pressure below $30 \mathrm{~cm} \mathrm{H}_{2} \mathrm{O}$ and peak airway pressure below $38 \mathrm{~cm} \mathrm{H}_{2} \mathrm{O}$ throughout the course of ventilation. The difference between the peak airway pressure and the plateau pressure was 6-9 $\mathrm{cm} \mathrm{H}_{2} \mathrm{O}$. We frequently checked for and ruled out intrinsic PEEP after each ventilator setting change. As recommended by the ventilator manufacturer, we frequently performed the "short self-test," especially after every ventilator setting change. The ventilator passed all the short self-tests, so we ruled out ventilator malfunction. Hypermetabolic conditions such as malignant hyperthermia, pheochromocytoma, and hyperthyroidism were unlikely, because the ABGs showed pure respiratory acidemia. We also ruled out all the expected causes of elevated $\mathrm{CO}_{2}$ production, so we concluded that the high $\mathrm{P}_{\mathrm{aCO}_{2}}$ was due to rebreathing of expired gas, probably due to too much ventilation dead space. Substantial dead space due to mas- sive pulmonary embolism was thought unlikely because he remained hemodynamically stable, with a low alveolararterial oxygen difference, then transesophageal echocardiogram ruled out pulmonary embolism.

To assess whether the problem had to do with the ventilator or ventilator circuit, we disconnected the patient from the ventilator and manually ventilated with a resuscitation bag, and an $\mathrm{ABG}$ obtained 5 min later showed substantial improvement of the hypercarbia (Table 1, setting 5). After further assessment of the ventilator and ventilator circuit we determined that an inappropriate circuit type was causing rebreathing and, thus, the hypercarbia. We immediately changed to a partitioned-lumen ventilator circuit, then set the ventilator to assist control mode, respiratory rate 14 breaths/min, tidal volume of $700 \mathrm{~mL}$, PEEP $5 \mathrm{~cm} \mathrm{H} \mathrm{H}_{2} \mathrm{O}$, and $\mathrm{F}_{\mathrm{IO}_{2}}$ 0.6. ${ }^{1}$ Subsequent ABGs were within the normal range. He was then weaned and extubated after 3 hours. A root-cause analysis investigation after the incident found that our supply of partitionedlumen circuits was not adequate for the seasonal increase in need, and lack of familiarity with and understanding of the need for a partitioned-lumen circuit among our respiratory therapists and house staff led to the use of an old circuit and failure to recognize it as different from the partitioned-lumen circuit (Fig. 1). We increased the minimum quantity of partitioned-lumen circuits in stock, mandated quarterly inspections to remove outdated supplies, and added ventilator-management educational materials to the respiratory therapists' annual required competency training.

\section{Discussion}

In our patient, who had severe COPD and was on mechanical ventilation, possible causes of the elevated $\mathrm{P}_{\mathrm{aCO}_{2}}$ included endotracheal tube obstruction, ventilator asynchrony, pneumothorax, bronchospasm, dynamic hyperinflation, elevated expiratory resistance, and elevated alveolar dead space due to tachypnea or pulmonary embolus, all of which we considered and excluded based on phys- 


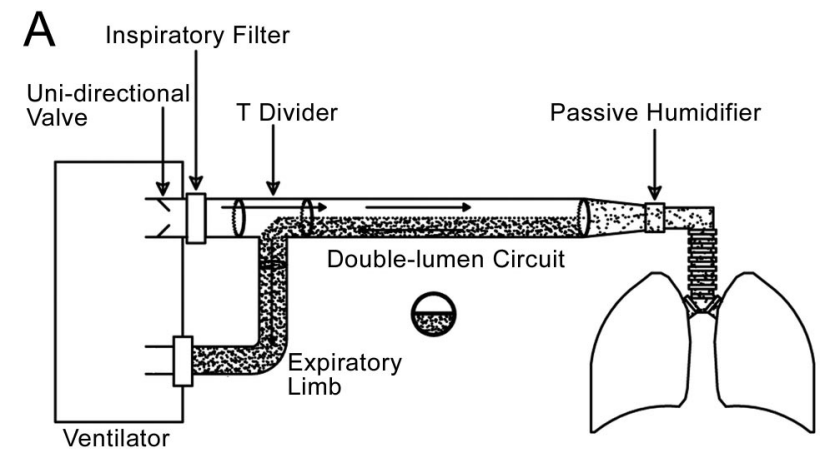

B

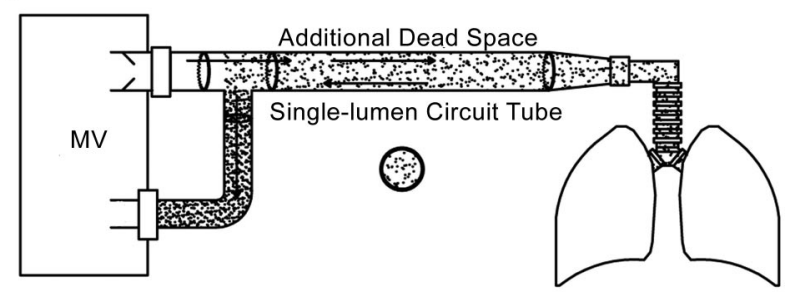

Fig. 1. A: Correct connection of the circuit with a partitioned-lumen circuit. B: Incorrect connection with an unpartitioned-lumen circuit.

ical examination and laboratory data. The next possibility was ineffective mechanical ventilation, including ventilator malfunction or incorrect assembly of the ventilator circuit. The traditional ventilator circuit has both an inspiratory and an expiratory limb, which join at the patient Y-piece. This configuration is simple, effective, and economical, but recently there has been a movement to adopt the single-tube partitioned-lumen circuit, which keeps inspiratory and expiratory gas separate for longer than does a unpartitioned-lumen circuit and thus decreases dead space, decreases circuit weight on the endotracheal tube or tracheostomy, enhances passive humidification of the inspired gas, and decreases apparatus footprint. ${ }^{4}$

We use the Limb-O partitioned-lumen circuit (Vital Signs/GE Healthcare, Totowa, New Jersey), which is transparent and has a bright blue stripe that marks the membrane that divides the circuit into halves to separate the inspiratory and expiratory lumens. ${ }^{4}$ The T-piece at the proximal end connects to the inspiratory and expiratory outlet pilot tubing.

The single-lumen circuit that we erroneously used in our patient had about $700 \mathrm{~mL}$ more dead-space volume than a partitioned-lumen circuit, which accounted for the patient's almost entire tidal volume (Fig. 2). Essentially, he was rebreathing his volume with intermittent tidal volumes being delivered into a turbulent rebreathing system. The delay in diagnosing the rebreathing could have caused hypoxia, prolonged severe acidosis, and severe cardiac depression. ${ }^{5}$ Escalation of incorrect treatment such as mus-
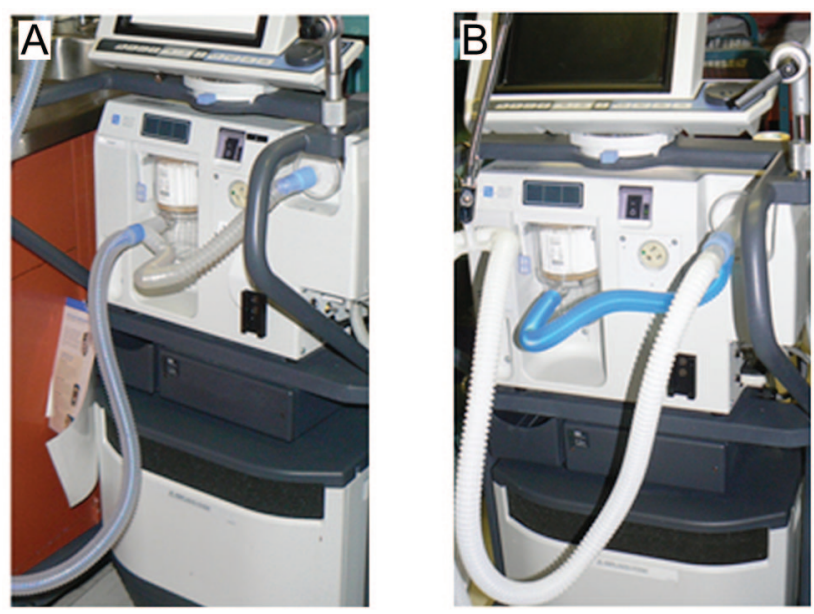

Fig. 2. A: Correct connection of the Limb-O partitioned-lumen circuit to the ventilator. B: Incorrect connection with an unpartitioned-lumen circuit. Notice the color difference between the 2 circuits.

cle paralysis and increasing the $\dot{\mathrm{V}}_{\mathrm{E}}$ (which created the risk of volutrauma) could have harmed him further.

In 2002 the Joint Commission reported a high percentage of death and injuries related to malfunction or misuse of ventilator alarms, tubing disconnection, and dislodged endotracheal tubes, which clearly supports the need for additional monitoring of the integrity of the ventilation apparatus. ${ }^{6}$ Capnography, which is cost-effective and is the standard of care in the operating room, has also been adopted, but not widely, in some intensive care units and during patient transport. ${ }^{7,8}$ The key component is how to use the information capnography provides. ${ }^{9}$ In our patient, if we had used capnography, the high inspired $\mathrm{CO}_{2}$ level could have been detected early and provided earlier management of the problem. We advocate routine capnography use in all settings where there is even a minimal chance of respiratory complications and when mechanical ventilation is used.

The simple way to detect a malfunction of an anesthesia machine or a mechanical ventilator is to disconnect the patient from the machine and use a resuscitation bag, which allows easy evaluation and troubleshooting of such problems without compromising patient care. We recommend doing this at an early stage, before proceeding to unnecessary management options that may not be cost-effective and may have a risk/benefit ratio that is not justified.

Our patient's case highlights the importance of having clinicians who not only understand the patient's clinical condition and ventilator management, but also the importance of clearly understanding all the patient-ventilator interactions. We hope that this case will be part of ventilator malfunctions reporting that increases the awareness 


\section{Non-Partitional Ventilator Tubing Results in Dead-Space Ventilation Hypercarbia}

of the necessity of adopting a process-improvement protocol via error assessment and intervention.

\section{REFERENCES}

1. Hedenstierna G, Sandhagen B. Assessing dead space: a meaningful variable? Minerva Anestesiol 2006;72(6):521-528.

2. Bnumolf J. Respiratory physiology and respiratory function during anesthesia. In: Miller RD. Anesthesia, 5th edition. Philadelphia: Churchill Livingstone; 2000:610-611.

3. Stock MC. Respiratory function in anesthesia. In: Barash PG, Cullen BF, Stoelting RK, editors. Clinical anesthesia, 5th edition. Philadelphia: Lippincott William \& Wilkins; 2006:801-804.

4. Vital Signs. Limb-O single limb breathing circuits. http://vital-signs. gehealthcare.com/html/english/products/respiratory/documents/ accc02981009enus.pdf. Accessed March 10, 2011.
5. Paterson JG, Vanhooydonk V. A hazard associated with improper connection of the Bain breathing circuit. Can Anaesth Soc J 1975; 22(3):373-377.

6. The Joint Commission. Sentinel event alert, issue 25: preventing ventilator-related deaths. http://www.jointcommission.org/sentinel_ event_alert_issue_25_preventing_ventilator-related_deaths_and_ injuries. Accessed March 10, 2011.

7. Zwerneman K. End-tidal carbon dioxide monitoring: a vital sign worth watching. Crit Care Nurs Clin N Am 2006;18(2):217-225.

8. Hinkelbein J, Floss F, Denz C, KrieterH. Accuracy and precision of three different methods to determine $\mathrm{P}_{\mathrm{aCO}_{2}}\left(\mathrm{P}_{\mathrm{aCO}_{2}}\right.$ vs $\mathrm{ETCO}_{2}$ vs. $\mathrm{P}_{\mathrm{aCO}}$ ) during interhospital ground transport of critically ill and ventilated adults. J Trauma 2008;65(1):10-18.

9. Cheifetz IM, MacIntyre NR. Respiratory controversies in the critical care setting: conference summary. Respir Care 2007;52(5): 636-644. 